Voix et Images

voixetimages

\title{
Le Burlesque, ou mourir de rire
}

\section{Jean Cléo Godin}

Volume 15, numéro 2 (44), hiver 1990

Pratiques illicites

URI : https://id.erudit.org/iderudit/200843ar

DOI : https://doi.org/10.7202/200843ar

Aller au sommaire du numéro

Éditeur(s)

Université du Québec à Montréal

ISSN

0318-9201 (imprimé)

1705-933X (numérique)

Découvrir la revue

Citer cet article

Godin, J. C. (1990). Le Burlesque, ou mourir de rire. Voix et Images, 15(2),

286-288. https://doi.org/10.7202/200843ar d'utilisation que vous pouvez consulter en ligne.

https://apropos.erudit.org/fr/usagers/politique-dutilisation/ 


\section{Le Burlesque, ou mourir de rire}

\section{Jean Cléo Godin, Université de Montréal}

Après un premier ouvrage consacré au burlesque québécois - le Burlesque au Québec: un divertissement populaire, paru chez HMH en 1981 - voici que Chantal Hébert élargit son champ de recherche en situant ce genre dramatique dans le grand ensemble américain dont il est tributaire. Le Burlesque québécois et américain ${ }^{1}$ reprend avec quelques modifications le texte de sa thèse soutenue en 1984 à l'université Laval. L'ouvrage omet cependant les trois dernières " annexes " de la thèse, dont un "répertoire du théâtre burlesque présenté à Montréal de 1920 à 1957 ». Ce seul répertoire faisait 175 pages et on comprend que, vu sa longueur, on ait jugé bon de le sacrifier; il constitue cependant un précieux instrument de recherche et mériterait de connaître une certaine forme de diffusion ${ }^{2}$.

Le burlesque demeure l'une des formes les plus importantes de théâtre populaire que le Québec, à l'instar des États-Unis quelques années avant lui, ait connu pendant près d'un demi-siècle (p. 4). Il faut bien comprendre et accepter ce constat, pour saisir le projet de Chantal Hébert, qui ne cherche ni à grandir ni à dévaloriser un genre qu'on persiste à situer en marge de l'institution théâtrale, mais qui a constitué le coeur de l'activité théâtrale à Montréal, de 1920 à 1950. Comment fonctionne ce système? D'où vient-il? Comment, à partir d'un modèle venu d'ailleurs, a-t-il pris racine au Québec? Voilà les questions auxquelles Chantal Hébert tente de répondre. 
Aussi le plus original et le plus précieux de cette analyse tient-il au souci de rétablir le lien avec le modèle américain. Cette approche a également été utilisée par Jean-Marc Larrue, dans sa thèse sur "L'activité théâtrale à Montréal de 1880 à 1914" (Université de Montréal, 1987), qui a clairement démontré que, pour cette période, on ne peut bien comprendre ce qui se passe si on se limite au théâtre de langue française et si on ne regarde pas ce qui se fait à New York. Même chose pour le burlesque qui a suivi cette période. Dans son premier ouvrage, Chantal Hébert avait déjà montré limportance de la "filière ontarienne", représentée par Olivier Guimond père et Arthur Pétrie. Mais celui-ci, par exemple, se procurait aux ÉtatsUnis la plus grande partie du matériel dont Juliette Pétrie a hérité (p. 38) et qu'on adaptait ensuite pour la scène québécoise. C'est donc ces textes américains qu'il fallait aller voir et Chantal Hébert a réuni un "corpus québécois" et un "corpus américain" comptant chacun 75 titres; pour chaque corpus, les textes de trois sketches sont également publiés intégralement. Même si (on s'y attendait) ces textes n'ont rien du chef-d'œuvre littéraire, leur publication constitue un événement d'autant plus important que le burlesque se caractérise par un rapport de méfiance envers l'écrit, celui-ci ne servant que de point d'appui d'un jeu par ailleurs très strictement codé, mais faisant une large place à l'improvisation.

$\mathrm{Si}$ les conclusions tirées de la comparaison entre ces deux corpus paraissent un peu minces, il ne faut pas s'en étonner: c'est que le registre du burlesque est lui-même fort limité, les sketches étant construits autour du couple comic / straight, et ne traitant guère que d'argent ou de sexe. C'est là, justement, que l'auteure repère les principales "variétés nationales" du burlesque québécois. La Québécoise semblerait lier l'argent à son autonomie, l'Américaine au lucre (p. 236). De façon générale, du reste, la tradition américaine (où le public est surtout masculin) est plus grivoise et les histoires de couchettes sont explicitement liées au désir sexuel, alors qu'au Québec (où le public est surtout composé de femmes), le mariage aurait servi [...] de paravent à la quête de la libido (p. 237). Fort juste et l'on comprend aisément pourquoi. Il me semble pourtant que l'auteure néglige ici la puissance de certaines évocations qui étaient certainement saisies par ce public. Ainsi les noms des personnages - le major "Fusilraide" (p. 235) ou, par exemple, les nombreux canevas où, comme par hasard, le prétendant s'est enrichi dans la saucisse ne transforment-ils pas des situations apparemment banales ou "honnêtes " en des histoires fort salaces?

La méthode adoptée pour l'analyse de ces canevas ne permettait peut-être pas de débusquer tous ces sous-entendus et doubles sens, et c'est justement sur cette méthode que j'entretiens des réserves. L'auteur explique fort bien qu'elle utilise la grille des "programmes narratifs» (p. 55) du Groupe d'Entrevernes, qu'elle complète par les modèles structuraux (paires de contraires, p. 59) de Kongas-Maranda et Maranda. Cela permet de dégager des structures signifiantes d'une belle clarté; les tableaux 4 et 5 m'ont à cet égard paru très utiles. Mais l'analyse détaillée où s'opposent les divers PN (pour programmes narratifs), le sujet et l'objet, l'être et le paraître, le conjoint et le disjoint, conduit à des formules d'une involontaire drôlerie. Jugez-en: La femme a un être à camoufler sous un paraître, ce qui veut dire qu'elle veut dissimuler une tromperie réelle à l'aide d'une fausse tromperie (p. 206). Et comment ne pas tiquer, à la même page (nous 
qui croyons qu'un mari est un conjoint) devant cette formule: le mari devient conjoint d'un savoir dont il était disjoint? Jaurais, ma foi, préféré des analyses moins scientifiques, mais plus pertinentes. On réfere dans ce livre quatre fois à Bakhtine, mais pourquoi ne s'être jamais inspiré de sa notion du carnavalesque? Cela aurait pu, par exemple, donner une autre dimension à l'inversion du haut et du bas (p. 114), comme au thème du cocuage (p. 150-156) et, surtout, au développement sur le défi à l'autorité qui coifferait l'ensemble de la production québécoise et américaine (p. 232-233) et dont il est encore question dans les dernières pages de ce livre, sous un beau titre: «Divertir et subvertir» (p. 256). Oui, le burlesque - québécois aussi bien qu'américain - n'est pas simple divertissement; il est aussi, à travers le rire et l'irrévérence, subversion des règles morales et sociales. C'est cet aspect du burlesque que Gélinas avait bien compris, et cela a donné les sketches les plus critiques des Fridolinades.

Fort à propos, Chantal Hébert termine son analyse sur un examen de Mort en riant, un texte donné en annexe et qu'il faut absolument lire. C'est un texte où l'autorité meurt... en riant (p. 251). Il n'y a pas de finale qui convienne mieux au burlesque!

1 Chantal Hébert, le Burlesque québécois et américain, Québec, les Presses de l'université Laval, 1989, 331 p. (CRELIQ/Vie des lettres québecoises, $n^{\circ} 27$ ).

2 Je signale qu'on peut évidemment le consulter à la bibliothèque de l'université Laval. Un exemplaire de cette annexe est également déposé au Centre d'études québécoises de l'Université de Montréal. 